\title{
Evaluation of prophylactic Effect of Remifentanil on Succinylcholine-Induced Myalgia in Humans
}

\author{
Karim Nasseri ${ }^{1 *}$, Mehdi Taibi Arasteh ${ }^{2}$, Abdorrahim Afkhamzadeh $^{3}$ and Saeed \\ Hakhamaneshi ${ }^{4}$ \\ ${ }^{1}$ Department of Anesthesia and Intensive Care, Kurdistan Research Center for Social Determinants of Health. (KRCSDH), \\ School of Medicine, ${ }^{2}$ Department of Anesthesia and Intensive Care, ${ }^{3}$ Department of Community Medicine, Kurdistan Research \\ Center for Social Determinants of Health, (KRCSDH), ${ }^{4}$ Department of Microbiology, Kurdistan University of Medical Sciences, \\ Sanandaj, Iran
}

*For correspondence: Email: nasseri_k@muk.ac.ir; Tel: 00988716660733; Fax: 00988713285890

\begin{abstract}
Purpose: To assess the efficacy of remifentanil in preventing succinylcholine-induced myalgia in humans.

Methods: Sixty healthy adults scheduled for elective surgery under general anesthesia were enrolled in a double-blind study and randomly allocated to two groups of thirty patients. Patients in Group I (remifentanil group) were pretreated with remifentanil $1 \mu \mathrm{g} / \mathrm{kg}$ one minute prior to induction of anesthesia, while patients in Group II (saline group) received an equivalent volume of saline. Anesthesia was induced in both groups with fentanyl $1 \mu \mathrm{g} / \mathrm{kg}$, propofol $2.0 \mathrm{mg} / \mathrm{kg}$ and succinylcholine $1.5 \mathrm{mg} / \mathrm{kg}$. Postoperative myalgia was assessed 12, 24, and $48 \mathrm{~h}$ after induction and graded as nil, mild, moderate, or severe.

Results: Fifty nine patients completed the study. The demographic data for both groups were comparable $(p>0.05)$. Postoperative myalgia at 12,24 , and $48 \mathrm{~h}$ after induction were $34.5,34.5$ and $14.1 \%$ in group $I$, and $60,53.4$ and $30 \%$ in group II, respectively $(p>0.05)$.

Conclusion: Prophylactic use of remifentanil $1 \mu \mathrm{g} / \mathrm{kg}$ intravenously is ineffective in the prevention of postoperative myalgia
\end{abstract}

Keywords: Remifentanil, Succinylcholine, Myalgia, Propofol, Prophylaxis

Tropical Journal of Pharmaceutical Research is indexed by Science Citation Index (SciSearch), Scopus, International Pharmaceutical Abstract, Chemical Abstracts, Embase, Index Copernicus, EBSCO, African Index Medicus, JournalSeek, Journal Citation Reports/Science Edition, Directory of Open Access Journals (DOAJ), African Journal Online, Bioline International, Open-J-Gate and Pharmacy Abstracts

\section{INTRODUCTION}

Succinylcholine (Sch), a depolarizing muscle relaxant with unique properties of rapid onset and short duration of action, remains the drug of choice for rapid-sequence induction of anesthesia in many countries [1]. It also seems to be a popular muscle relaxant for ambulatory anesthesia and short surgical procedures [2]. It is regularly used by $69 \%$ of anesthesiologists and in $97 \%$ of emergency surgeries in Europe and the USA for adults [3]. Sch has unique advantages, including low cost, fast onset of action, rapid recovery, benign metabolites, and reliable degree of relaxation [4,5] .These could be the reason for the use of the drug for more than 60 years.

Postoperative myalgia (POM) is a frequent side effect of succinylcholine administration [6]. The incidence of myalgia at the first $24 \mathrm{~h}$ after operation has been reported to range from 1.5 to $92 \%$ [7]. The pathogenesis of POM is not clear, and pretreatment with non-depolarizing muscle 
relaxants apparently fails to reduce the incidence and intensity [8]. Myalgia may go along with muscle stiffness, and can last for several days and induce significant discomfort [6].

Remifentanil is a $\mu$-receptor opioid agonist with unique properties such as rapid onset, and short duration of action [9]. Remifentanil can attenuate the intensity and duration of succinylcholineinduced fasciculation $[10,11]$ but the effect of remifentanil on POM has not evaluated, to the best of our knowledge. The purpose of this study was to determine the incidence and severity of succinylcholine-induced POM in patients pretreated with saline or remifentanil.

\section{EXPERIMENTAL}

After approval by Ethical Committee of Kurdistan University of Medical Sciences, Sanandaj, Iran, the study was enrolled in Iranian Registry of Clinical Trials (IRCT.ir, ID: 138810141766N3). IRCT is a primary registry in the World Health Organization (WHO) registry network set up with the help of Iran Ministry of Health and Medical Education. IRCT follows International Ethical Guidelines for Biomedical Research Involving Human Subjects, prepared by the Council for International Organizations of Medical Sciences in collaboration with the WHO.

Following permission from the administration of Besat Teaching Hospital, Sanandaj, Iran which is the largest public hospital in the Kurdistan province of Iran, and after receiving written informed consent from the participants, sixty adult patients of American Society of Anesthesiologists physical status I - III, aged between 18 and 60 years, who were scheduled to receive elective lower abdominal surgery under general anesthesia, were recruited in our study.

Exclusion criteria was a history of any systemic disease, neuromuscular problems or malignant hyperthermia, pregnancy, patients with anticipated airway difficulty, morbid obesity, and history of drug abuse.

\section{Randomization and blinding}

Using a computer-generated table of numbers participants were enrolled in a double-blind randomized controlled clinical trial, and allocated in two equal groups of 30 to receive premedication (remifentanil or normal saline). The preparation and injection of study drugs were performed by an anesthesia nurse who was not aware of type of injected drugs, and data collection. Data were collected by a trained nurse under the supervision of an anesthesiologist who was blinded for the pretreatment drug. The patients, those administering the drugs, and those gathering the information were unaware of the medicine used in each group.

After establishing standard monitoring, all patients received midazolam $1 \mathrm{mg}$, fentanyl 1 $\mu / \mathrm{kg}$ and lidocaine $1 \mathrm{mg} / \mathrm{kg}$. Two 2 minutes later, the patients received one of the following drugs based on their groups (remifentanil $1 \mu / \mathrm{kg}$ in study group and $5 \mathrm{ml}$ normal saline in control group). The induction regimen was the same for two groups and included propofol $(2 \mathrm{mg} / \mathrm{kg}$, IV) and succinylcholine $(1.5 \mathrm{mg} / \mathrm{kg}$, IV) for muscle relaxation. At the end of fasciculation, trachea was intubated. Maintenance of anesthesia was achieved with $60 \% / 40 \%$ nitrous oxide /oxygen and $0.5-1.5 \%$ isoflurane.

Myalgia was assessed 12,24 , and $48 \mathrm{~h}$ after operation and graded according to Kararmaz et al [12] four points scale: absence of muscle pain $=$ nil or 0 , minor stiffness limited to one area of the body $=$ mild or 1 , muscle pain or stiffness, which may require analgesic therapy $=$ moderate or 2, incapacitating generalized muscle stiffness or pain = severe or 3 ). The duration of visible muscle fasciculation were assessed too.

\section{Statistical analysis}

By using the statistical software, it was estimated that 30 patients per group was needed to obtain $80 \%$ statistical power, at the $95 \%$ significance level, for reducing $25 \%$ incidence and severity of myalgia in comparison with the control group.

For analysis of data, we used the SPSS 16 (Chicago, IL, USA). Variables such as age and weight were analyzed with one-way analysis of variance. Comparison of severity of myalgia and fasciculation was performed using Student's ttest, and/or Fisher's exact test. $P<0.05$ was considered statistically significant.

\section{RESULTS}

Due to withdrawal of consent, one patient was excluded from the study; therefore extracted data from 59 patients were analyzed. Patients in both groups were comparable in respect to age, sex, and weight (Table 1). Duration of fasciculation was slightly lower in remifentanil group $(p=0.2)$, however the severity of fasciculation were not different. There were no significant differences between two groups in respect to myalgia (Table 2). 
Table 1: Demographic data for patients of both groups

\begin{tabular}{lccc}
\hline $\begin{array}{l}\text { Group } \\
\text { variable }\end{array}$ & $\begin{array}{c}\text { Remifentanil } \\
\mathbf{N}=\mathbf{2 9}\end{array}$ & $\begin{array}{c}\text { Saline } \\
\mathbf{N}=\mathbf{3 0}\end{array}$ & $\boldsymbol{P}$-value \\
\hline Sex $(\mathrm{M} / \mathrm{F})$ & $19 / 10$ & $20 / 10$ & 0.5 \\
Age $(\mathrm{yrs})$ & $33.3 \pm 11.7$ & $29.9 \pm 11.5$ & 0.2 \\
Weight $(\mathrm{kg})$ & $68.1 \pm 11$ & $71.3 \pm 14.9$ & 0.3 \\
\hline
\end{tabular}

Table 2: Duration, incidence, and severity of fasciculation and myalgia

\begin{tabular}{|c|c|c|c|}
\hline $\begin{array}{l}\text { Group } \\
\text { variable }\end{array}$ & $\begin{array}{c}\text { Remifentanil } \\
\mathrm{N}=29\end{array}$ & $\begin{array}{c}\text { Saline } \\
\mathrm{N}=30\end{array}$ & $P$-value \\
\hline Duration of fasciculation (min) & $21 \pm 14$ & $26 \pm 20$ & 0.2 \\
\hline Severity of myalgia in the first $6 \mathbf{h}$ & & & 0.5 \\
\hline Zero & $29(100 \%)$ & $29(96.7 \%)$ & \\
\hline One & $(0 \%)$ & $1(3.3 \%)$ & \\
\hline Two & $0(0 \%)$ & $0(0 \%)$ & \\
\hline Three & $0(0 \%)$ & $0(0 \%)$ & \\
\hline Severity of myalgia in the first $12 \mathrm{~h}$ & & & 0.9 \\
\hline Zero & $19(65.5 \%)$ & $12(40 \%)$ & \\
\hline One & $8(27.6 \%)$ & $15(50 \%)$ & \\
\hline Two & $2(6.9 \%)$ & $3(10 \%)$ & \\
\hline Three & $0(0 \%)$ & $0(0 \%)$ & \\
\hline Severity of myalgia in the first $24 \mathrm{~h}$ & & & 0.6 \\
\hline Zero & $19(65.5 \%)$ & $14(46.6 \%)$ & \\
\hline One & $9(31 \%)$ & $11(36.7 \%)$ & \\
\hline Two & $1(3.4 \%)$ & $5(16.7 \%)$ & \\
\hline Three & $0(0 \%)$ & $0(0 \%)$ & \\
\hline Severity of myalgia in the first $48 \mathrm{~h}$ & & & 0.5 \\
\hline Zero & $25(86.2 \%)$ & $22(73.4 \%)$ & \\
\hline One & $3(10.3 \%)$ & $4(13.3 \%)$ & \\
\hline Two & $1(3.4 \%)$ & $4(13.3 \%)$ & \\
\hline Three & $0(0 \%)$ & $0(0 \%)$ & \\
\hline
\end{tabular}

\section{DISCUSSION}

The results of this double-blind, placebocontrolled clinical trial demonstrated that adding remifentanil to propofol can shorten the duration of fasciculation; however this decrease is not statistically significant. Also, the intensity of fasciculation in two groups was not significantly different.

This result is inconsistent with the results of our previous study and study conducted by Yun et al $[10,11]$. The reasons of incompatibility between the results of our previous study with present study are unclear, because the situations and patients in both studies were similar.

The only justifications that can be achieved are that visual measurement of duration of fasciculation could give different results and areas of the body that observer looks to assess the fasciculation may alter the results. Because the whole body of patients is not exposed during anesthesia, and this could create a bias in the results. The duration of fasciculation was higher in patients of both groups in Yun's study [11], compared to our study. They used remifentanil $1.5 \mu \mathrm{g} / \mathrm{kg}$ as a pretreatment, which was 1.5 times of the dose we used.
The other difference is related to the dose of succinylcholine, which; unlike to the dose of remifentanil; was higher in our study. Another difference is that we used fentanyl $(1 \mu \mathrm{g} / \mathrm{kg})$ prior to injection of remifentanil in both groups.

There are some reports that increasing the succinylcholine dose can decrease frequency of severe fasciculation [13]. Also, according to some reports, propofol in higher doses (3 mg/kg) can decrease the severity and frequency of sever fasciculation in comparison to lower doses (2 $\mathrm{mg} / \mathrm{kg}$ ) and thiopental [12]. We used propofol in doses similar to the study of Karamaz et al [12]. Therefore we cannot assume that decrease in duration of fasciculation is related only to the use of propofol.

The other factor that was checked in our study was myalgia. Based on findings of this study, pretreatment with remifentanil has no effect on postoperative myalgia. These findings are consistent with findings of Yun et al [11].

Schreiber et al in their meta-analysis concluded that induction of anesthesia with thiopental in comparison to propofol can decrease incidence of myalgia from 65 to $49 \%$ [14]. Another measure which was effective in reducing myalgia 
is increase in the dose of succinylcholine [15]. Adding opioid to premedication drugs during induction of anesthesia was ineffective in reducing incidence and severity of myalgia [14]. Pretreatment with $10-30 \%$ of $95 \%$ effective dose of non-depolarizing muscle relaxants is another way to decrease incidence of myalgia [16].

In our study, pretreatment with remifentanil in comparison to saline decreased significantly blood pressure and heart rate during induction of anesthesia with propofol. These cardiovascular changes were continued after tracheal intubation, as four patients in remifentanil group and one patient in saline group were required to injection of ephedrine. Remifentanil can decrease sympathetic nervous system activity during tracheal intubation, but bradycardia and hypotension are its side effects [17]. Muscle rigidity is another drawback of remifentanil, but it was not seen in this study.

\section{CONCLUSION}

Pretreatment with remifentanil in patients who received propofol for induction of anesthesia and succinylcholine for muscle relaxation can reduce the severity of fasciculation, but has no effect on duration of fasciculation, as well as on frequency and severity of myalgia. Decrease in sympathetic response to laryngoscopy and tracheal intubation is another positive effect of this pretreatment.

\section{ACKNOWLEDGEMENT}

The authors gratefully acknowledge Kurdistan University of Medical Sciences for partial support for this study.

\section{REFERENCES}

1. Pandey CK, Tripathi M, Joshi G, Karna ST, Singh $N$, Singh PK. Prophylactic use of gabapentin for prevention of succinylcholine-induced fasciculation and myalgia: A randomized, double-blinded, placebocontrolled study. J Postgrad Med 2012; 58: 19-22.

2. Mencke T, Schreiber JU, Becker C, Bolte M, Fuchs Buder T: Pretreatment before succinylcholine for outpatient anesthesia? Anesth Analg 2002; 94:573576.

3. Karanovi N, Carev M, Kardum G, Tomanović N, Stuth E, Gal J, Tonković-Capin M, Dogas V, Racić G, Dogas Z. Succinylcholine Use in Adult Anesthesia -A
Multinational Questionnaire Survey. Coll. Antropol 2011; 35(1): 183-190.

4. Lee $C$, Katz RL. Clinical implications of new neuromuscular concepts and agents: So long, neostigmine! So long, sux! J Crit Care 2009; 24: 4349.

5. El-Orbany M, Connolly LA. Rapid Sequence Induction and Intubation: Current Controversy. Anesth Analg 2010; 1; 110(5): 1318-1325.

6. Wong SF, Chung F. Succinylcholine-associated postoperative myalgia. Anaesthesia 2000; 55: 144152.

7. Smith I, Ding Y, White PF. Muscle pain after outpatient laparoscopy-influence of propofol versus thiopental and enflurane. Anesth Analg 1993; 76: 1181-1184.

8. Schreiber JU, Mencke T, Biedler A, Fürst O, Kleinschmidt $S$, Buchinger $H$, Fuchs-Buder T. Postoperative myalgia after succinylcholine: no evidence for an inflammatory origin. Anesth Analg 2003; 96:16401644.

9. Rosow CE. An overview of remifentanil. Anesth Analg 1999; 89: S1-3.

10. Nasseri K, Arasteh MT, Shami Sh. Pretreatment with remifentanil is associated with less succinylcholineinduced fasciculation. Middle East $J$ Anesthesiol 2010; 20(4): 515-520.

11. Yun MJ, Kim YH, Go YK, Shin JE, Ryu CG, Kim W, Paik NJ, Han MK, Do SH, Jung WS. Remifentanil attenuates muscle fasciculations by succinylcholine. Yonsei Med J 2010; 51(4): 585-589.

12. Kararmaz A, Kaya $S$, Turhanoglus $S$, Ozyilmaz MA..Effects of high-dose propofol on succinylcholineinduced fasciculations and myalgia. Acta Anaesthesiol Scand 2003; 47: 180-184.

13. Ghergherehchi $M$, Mehraein A, Sadeghi M. The influence of different doses of Succinylcholine over fasciculation and postoperative myalgia. Tehran Univ Med J 2002; 60(6): 477-482.

14. Schreiber J, Lysakowski C, Fuchs-Buder T, Tramer MR. Prevention of succinylcholine-induced Fasciculations and myalgia. A Meta Analysis of randomized trials. Anesthesiology 2005; 103: 877-884.

15. Mencke T, Schreiber JU, Becker C, Bolte M, FuchsBuder T. Pretreatment before succinylcholine for outpatient anesthesia? Anesth Analg 2002; 94(3): 573-576.

16. Abbas N, Tariq S, Khan AW, Murtaza G, Naqvi N, Khanzada $A$. To assess the effects of rocuronium pretreatment on succinylcholine induced fasciculations and postoperative myalgias. J Pak Med Assoc 2009; 59(12): 847-850.

17. Barclay K, Kluger MT. Effect of bolus dose of remifentanil on haemodynamic response to tracheal intubation. Anaesth Intensive Care 2000; 28(4): 403-407. 